\title{
Sentidos do PIBID para/na Formação de Professores de Matemática
}

\author{
Senses of the PIBID for/in the Mathematics Teachers Education
}

\author{
Viviane Cristina Almada de Oliveira*a; Jéssica Nascimento dos Santos ${ }^{\mathrm{b}}$; Rebeca Ramona Dias Rodrigues ${ }^{\mathrm{b}}$
}

${ }^{a}$ Universidade Federal de São João del-Rei, Departamento de Matemática e Estatística. MG, Brasil.

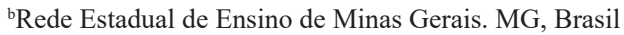

*E-mail: viviane@ufsj.edu.br

\begin{abstract}
Resumo
O artigo apresenta algumas considerações sobre o Programa Institucional de Bolsa de Iniciação à Docência (PIBID), focando, em especial, nas experiências de integrantes do subprojeto na área de Matemática da Universidade Federal de São João del-Rei (UFSJ). Inicialmente, apresentamos um breve histórico do programa na UFSJ e do subprojeto de Matemática (PIBID/Matemática) no curso de licenciatura em Matemática. Abordamos o diálogo entre a teoria e a prática, proporcionado pelo programa, através da articulação entre a universidade e a escola, por nós considerada como campo de formação do licenciando e do professor. Destacamos a importância do caráter coletivo de nossos trabalhos no PIBID/Matemática e das reflexões sobre nossas práticas. Trazemos à escrita algumas práticas realizadas no ensino público da cidade de São João del-Rei, colocando nossas considerações sobre como elas podem ter implicado em nossa formação docente. Embora reconheçamos o PIBID como uma iniciativa que contribuiu consideravelmente para a formação de professores no Brasil, ainda há muitos desafios a serem suplantados nessa área; em particular, a implementação de políticas de acompanhamento e acolhida do professor em início de carreira.
\end{abstract}

Palavras-chave: PIBID. Formação de Professores. Ensino de Matemática.

\begin{abstract}
The article reports some considerations about the Institutional Program of the Initiation to Teaching Scholarship (PIBID), focusing in particular on the experiences of members of the subproject in the Mathematics area of the Federal University of São João del-Rei (UFSJ). Initially, we present a brief history of the program in the UFSJ and the subproject of Mathematics (PIBID / Mathematics) in the degree course in Mathematics. We approach the dialogue between theory and practice, provided by the program, through the articulation between the university and the school, considered by us as formation locus. We emphasize the importance of the collective character of our work in PIBID / Mathematics and of the reflections on our practices. We discussed some practices carried out in public education in the city of São João del- Rei, placing our considerations on how they may have contributed to our teacher education. While recognizing PIBID as an initiative that has contributed significantly to teacher education in Brazil, there are still many challenges to be overcomed in this area; in particular, the implementation of follow-up and early teacher acceptance policies.
\end{abstract}

Keywords: PIBID. Teacher Education. Mathematics Teaching.

\section{Introdução}

São muitos os desafios contemporâneos no campo da formação de professores no Brasil. Um deles está na consolidação de práticas e na criação de uma cultura que favoreçam a inserção de licenciandos no cotidiano de escolas da educação básica; esse é um momento importante e decisivo na formação inicial de professores. Através do vínculo universidade-escola, instituições de ensino superior e básico têm uma oportunidade de trabalhar em colaboração para o aperfeiçoamento e para a valorização da educação e da profissão docente. Essa aproximação do futuro professor, ainda em formação, com a escola básica, pode possibilitar ainda que a universidade contribua na busca pelo suprimento de algumas demandas educacionais existentes na própria comunidade escolar.

Dentre essas demandas podemos destacar, segundo Gatti e Barreto (2009), a carência de professores em todos os níveis do processo de ensino, ocasionada pela expansão da oferta de educação básica e pelos esforços de inclusão social, e a necessidade de práticas educativas que possam colaborar na construção de uma sociedade justa e democrática. Nesse horizonte, um dos desafios apontados por essas autoras à formação de professores está na necessidade de se estabelecer processos formativos vinculados à realidade das escolas de educação básica para elevação do nível de desenvolvimento profissional docente.

Por isso, vêm se tornando cada vez mais imprescindíveis ações governamentais que invistam no aprimoramento da formação de professores e que se convertam em mais qualidade na educação promovida em escolas da rede pública de ensino brasileira. Ações que não só invistam na formação de profissionais qualificados, mas que também possibilitem a sua permanência no exercício da docência e que incentivem o aperfeiçoamento daqueles que já atuam na área.

Em virtude disso, o Ministério da Educação (MEC) tem 
lançado, sobretudo na última década, projetos de incentivo à docência. Um deles é o Programa Institucional de Bolsas de Iniciação à Docência (PIBID), criado em 2008, numa parceria com a Coordenação de Aperfeiçoamento de Pessoal de Nível Superior (CAPES).

A Portaria ${ }^{1}$ Normativa $n^{\circ} 16$, de 23/12/2009, do MEC, que dispõe sobre o PIBID e institui esse programa, indica como sua finalidade [...] o fomento à iniciação à docência de estudantes das instituições federais de educação superior, aprimorando-lhes a qualidade da formação docente em curso presencial de licenciatura de graduação plena e contribuindo para a elevação do padrão de qualidade da educação básica (Brasil, 2009, p. 91).

O PIBID, inicialmente, atendeu à formação de docentes para atuar nas Licenciaturas de Física, Química, Matemática e Biologia, devido à já citada carência de professores diagnosticada nestas áreas. No entanto, a partir de 2010, o Programa passou a congregar também os demais cursos de Licenciatura. Assim, o PIBID, regulamentado pelo Decreto no 7.219, de 24/06/2010, pôde vir a se tornar política pública e ser um incentivo para possibilitar a aproximação entre instituições representadas pela Universidade e pela escola (Brasil, 2010), ampliando a oportunidade de experiências fundamentais para a formação de professores.

Durante a participação no PIBID, alunos de cada curso de licenciatura eram orientados por um professor da mesma área do ensino básico (professor supervisor), sob a responsabilidade de um professor do ensino superior (professor coordenador de área). A CAPES disponibilizou apoio financeiro para o pagamento de bolsas a todos integrantes do programa durante o tempo em que ele vigorou.

A Universidade Federal de São João del-Rei (UFSJ) foi uma das pioneiras no desenvolvimento do PIBID no Brasil, como vemos em Oliveira (2014). Neste artigo, apresentamos um breve panorama desse programa dentro da UFSJ para, então, voltarmos nossa atenção mais especificamente ao desenvolvimento do subprojeto de Matemática do PIBID, que passaremos a denominar por PIBID/Matemática. Na sequência, discorremos sobre quais foram os sentidos do PIBID/Matemática para/na formação de professores de Matemática da UFSJ, sob as perspectivas de três bolsistas (duas de iniciação à docência e uma coordenadora de área) desse programa.

\section{O PIBID na UFSJ e o PIBID/Matemática}

Em 2008, a UFSJ submeteu seu primeiro projeto institucional para participar do PIBID. Após a aprovação do mesmo, tiveram início as atividades do referido programa no mês de fevereiro de 2009. A primeira edição do Programa da UFSJ foi desenvolvida em três escolas estaduais e uma escola municipal de São João del-Rei/MG pelo estabelecimento de parcerias entre a universidade a as Secretarias de Estado da Educação de Minas Gerais (SEE/MG) e Municipal de Educação de São João del-Rei. Dela, participaram 58 alunos bolsistas integrantes das seis licenciaturas que formaram esse primeiro grupo: Física, Química, Biologia, Pedagogia, Letras e Matemática.

Tais licenciaturas estiveram presentes nas escolas através da ação dos bolsistas, na busca pela identificação das necessidades existentes nos campos social e educacional de cada uma daquelas instituições. A partir desse momento, o Programa se encaminhou para a elaboração de projetos de ensino, oficinas e outras atividades a serem desenvolvidas no interior das escolas.

Em 2010, o projeto institucional foi ampliado com a participação de mais cinco Licenciaturas da UFSJ: Educação Física, Filosofia, Geografia, História e Teatro e, mais recentemente, em julho de 2011, foi inserida a licenciatura de Música no Programa.

Os objetivos do PIBID comungam com a Política de Extensão contida no Plano de Desenvolvimento Institucional da UFSJ, que afirma que "a Extensão se caracteriza pelo relacionamento da UFSJ com o meio externo e deve voltarse para as prioridades locais, regionais e nacionais" (Brasil, 2014, p.53).

O subprojeto de Matemática do PIBID-UFSJ teve início em 2009, no primeiro edital do programa, e compartilhou do objetivo central PIBID, que era "[...] incentivar novos profissionais para o exercício da docência no ensino básico, em escolas públicas" (Souto, Castro, Reis, \& Oliveira, 2010, p. 2). Ainda, como vemos em Souto et al. (2010) e Oliveira (2014), objetivou a capacitação dos licenciandos para o uso e produção de materiais alternativos ao livro didático de Matemática, procurando apontar diversas possibilidades para o trabalho com conteúdos importantes à educação básica.

Entre 2009 e fevereiro de 2018, o PIBID/Matemática teve duas coordenadoras de área. Nos quase dez anos de atividade desse projeto, ele configurou-se com um cenário marcado por discussões acerca de ações didático-pedagógicas que buscavam a progressão da qualidade do ensino básico, tendo em vista promover ações que se tornassem movimento na formação docente daquele grupo, composto por professores e futuros professores de Matemática.

Os modos como organizava-se o grupo para e no trabalho nas escolas foram alternados de tempos em tempos. Mas, invariavelmente, o grupo de bolsistas de iniciação à docência subdividia-se de acordo com o número de escolas parceiras $\mathrm{e}$, antes de dar início às intervenções propriamente em uma determinada escola, nela e nas turmas com as quais os subgrupos trabalhariam, realizavam-se observações.

Em um primeiro formato adotado, cada um dos três subgrupos de graduandos ocupava-se de estudar, estruturar, 
discutir e implementar nas escolas projetos de ensino, previstos para um tempo que variava entre 1 e 3 meses, os quais versavam sobre temáticas relacionadas aos blocos de conteúdos dos PCN (Parâmetros Curriculares Nacionais) de Matemática (Brasil, 1998) e aos eixos temáticos do CBC (Conteúdos Básicos Comuns) (Minas Gerais, 2007); eram eles: Tratamento da Informação, Álgebra, e Espaço e Forma. Esses subgrupos percorriam as escolas parceiras executando os projetos idealizados. Desse modo, pudemos experimentar o desenvolvimento de um mesmo projeto em diferentes contextos, percebendo como a realidade de cada escola, de cada turma, interferia na sua consecução.

Com essa primeira forma de organização, com os subgrupos fazendo rodízio nas escolas parceiras, não foi possível estreitar laços e criar vínculos com as instituições e, principalmente, com seus alunos. Optamos, assim, por um segundo formato, com cada um dos subgrupos de bolsistas atuando em uma escola específica. Assim tivemos mais chances de, pelo maior tempo de convívio e de imersão na mesma escola, de estudar, estruturar, discutir e implementar projetos de ensino que estivessem mais próximos das demandas específicas de cada uma delas.

O trabalho com projetos de ensino envolvia temáticas específicas relacionadas a questões sociais, políticas e culturais, as quais podiam ser lidas também com a lente da Matemática; um exercício de todo o grupo do PIBID/Matemática faziase pela avaliação crítica dos esboços e primeiras versões desses projetos, buscando aprimorá-los para a execução junto aos adolescentes e jovens das escolas parceiras. Embora esse jeito de funcionar, planejando e executando projetos de ensino em uma certa escola, ajudasse na confiança dos subgrupos em realizar atividades que se diferenciavam em vários aspectos das aulas ministradas pelos professores de Matemática responsáveis pelas turmas, também por isso, esse formato afastava os subgrupos do fazer docente do dia a dia, dos desafios enfrentados pelos professores naquelas aulas "comuns" de Matemática. Sendo assim, uma terceira forma de organização se deu pela opção em atuarmos nas escolas com os subgrupos em um novo formato, híbrido do trabalho com projetos de ensino e de aulas de Matemática, de acordo com os conteúdos previstos no planejamento anual dos professores.

De um modo geral, as intervenções planejadas para serem realizadas nas escolas - fossem elas dentro de projetos de ensino ou em aulas isoladas - buscavam deixar os alunos menos intimidados com a Matemática, sentindo-se convidados a se aproximarem mais dessa matéria escolar através das variadas oportunidades de aprendizado criadas.

Os planejamentos, discussões e reflexões sobre essas intervenções realizavam-se semanalmente, em reuniões na universidade, quando nossas experiências individuais e coletivas eram compartilhadas com todo o grupo, para que pudéssemos investigar e refletir sobre nossas ações pedagógicas. Fiorentini e Castro (2003, p.127) afirmam que "refletir, então, acerca do contexto no qual estamos inseridos, com suas limitações e possibilidades, permite-nos avançar por olhar o mundo escolar em sua dinâmica e complexidade". Assim, acreditamos que essas reflexões produzidas pelos bolsistas do PIBID, ao longo desses momentos de reunião, contribuíram para que aqueles futuros professores que ali estavam se sentissem impelidos e motivados a buscar alternativas metodológicas e didáticas que fossem ao encontro de criar na escola um ambiente propício para ensinar-aprender; assim, juntos, professores e futuros professores de Matemática, aprendíamos das experiências vivenciadas por alguns nas escolas e encontrávamos possibilidades de encaminhamento para o trabalho a seguir nos estudos e leituras que fazíamos coletivamente ou partilhávamos uns com os outros.

A oportunidade de trabalharmos coletivamente em um grupo composto por pessoas em diferentes estágios da carreira docente, proporcionou-nos discussões ricas, nas quais olhares diferentes sobre uma mesma situação foram socializados. Como nos disse Freire (2016, p. 40), "é pensando criticamente a prática de hoje ou de ontem que se pode melhorar a próxima prática". Assim, foram nesses momentos de produção colaborativa e de reflexão, que se mostraram importantes as práticas de compartilhamento de múltiplas perspectivas e também o caráter coletivo, característico do PIBID.

\section{Potencialidades do PIBID/Matemática para/na Formação de Professores de Matemática da UFSJ}

Nesta seção do artigo, traremos para a discussão aqueles que foram, para nós, os sentidos do PIBID/Matemática para/ na formação de professores de Matemática na UFSJ. Nossas considerações dizem respeito àquelas que foram, a nosso ver, as principais potencialidades desse programa de iniciação à docência, tanto para/na formação inicial dos licenciandos de Matemática quanto continuada de professores supervisores e coordenadora de área.

Para estabelecer uma organização do texto, optamos por tratar de alguns desses sentidos em subseções, cujos títulos são uma tentativa de anúncio do que naquele espaço será tratado. Entretanto, o caráter sistêmico desse programa em nossa formação tem também repercussão em nossa escrita: questões tratadas em uma subseção, inevitavelmente, são retomadas em outra. $\mathrm{O}$ trabalho coletivo, os novos significados produzidos para a prática educativa a partir da reflexão sobre a prática e da escrita sobre a prática, a aproximação entre escola e universidade, os elos criados entre teoria e prática e a (re) tradução de saberes escolares em nossas intervenções - cada um desses sentidos imbricados - como fios entrelaçados, são destacados da trama PIBID por nós tecida para a composição da sequência deste artigo.

\subsection{Ensinar e aprender não combinam com solidão: a importância do trabalho coletivo}

No âmbito do PIBID/Matemática, o enfrentamento dos desafios relacionados à (iniciação à) docência esteve sempre associado à certeza de que não estávamos sozinhos. O trabalho 
em grupo fez parte tanto dos momentos de estudo coletivo de toda equipe quanto dos momentos de planejamento e discussão de atividades e projetos.

Enquanto pibidianos, promovemos um espaço de constante criação em cooperação, muito além de o mero elaborar intervenções ou projetos de ensino. A pesquisa de materiais já existentes ou nosso esforço por produzir outros que pudessem atender aos objetivos que pautávamos para nossas intervenções, criavam momentos de aprendizado sobre conteúdos que achávamos que já conhecíamos e dominávamos. O esforço de pensar ações em grupo criaram os chamados espaços de partilha além das fronteiras escolares (Nóvoa, 2001). Assim, os bolsistas de iniciação à docência, ainda que em períodos diferentes da graduação, estavam a todo momento integrando-se, buscando coletivamente fazer o que então julgavam ser mais adequado na tentativa de oferecer oportunidades de qualidade para a aprendizagem de alunos da escola básica.

O saber outrora construído, dessa maneira, tomava nova direção, virava outro(s). Na busca por novos aprendizados, novas percepções surgiam e novos conhecimentos foram construídos por nosso grupo. Desse modo, a dinâmica de nossos encontros ajudou-nos a compreender que, de fato, "[...] os professores [e futuros professores] são construtores de conhecimento pedagógico de forma individual e coletiva." (Imbernón, 2015, p. 81, comentário nosso).

\subsection{Registro e reflexão: produzindo novos saberes da prática profissional}

Parte desse conhecimento construído por todos os envolvidos no PIBID/Matemática se deu pelos processos de reflexão que púnhamos em marcha, na medida em que atividades eram desenvolvidas nas escolas parceiras. Momentos de reflexão sobre o que se foi criado ou vivido eram parte de nossos encontros periódicos com todos os integrantes do projeto, afinal “[...] a gente se faz educador, na prática e na reflexão sobre a prática” (Freire, 1991, p. 58).

Esse constante ato de refletir sobre o vivido estava diretamente ligado ao nosso processo de escrita dos diários de campo.Eranesses diários onderegistrávamos, individualmente, todas nossas intervenções, como aconteceram, quais objetivos foram alcançados, o que era preciso mudar, compreender e superar para os próximos encontros na escola, na universidade e na nossa própria formação. Além dos diários de campo, os subgrupos do PIBID/Matemática produziam relatórios coletivos das intervenções realizadas.

Os comentários e discussões sobre as intervenções que aconteciam durante as reuniões com todo o grupo e o processo de escrita do registro das intervenções, tanto nos diários de campo quanto nos relatórios, proporcionavam a todos os envolvidos gerar outros conhecimentos, romper com certas barreiras, permitindo-nos lançar outros olhares sobre o vivido, sobre o experienciado. Obviamente, esses documentos não expressavam a totalidade dos pensamentos de cada um a respeito de si mesmo, dos outros, da escola e da própria formação. Contudo, eram aquelas palavras que nos ajudavam a sistematizar nosso pensar sobre nós mesmos, sobre os outros, sobre a escola e sobre nossa formação, afinal

[...] pensar não é somente "raciocinar" ou "calcular" ou "argumentar", como nos tem sido ensinado algumas vezes, mas é sobretudo dar sentido ao que somos e ao que nos acontece. [...] E, portanto, também tem a ver com as palavras o modo como nos colocamos diante de nós mesmos, diante dos outros e diante do mundo em que vivemos. (Larrosa, 2002, p.21)

A socialização de nossas ações também acontecia no âmbito institucional. Anualmente, desde 2012, a UFSJ promoveu o Seminário de Iniciação à Docência (SID), quando todas as áreas que compunham o PIBID da universidade apresentavam trabalhos relacionados às práticas e intervenções realizadas com alunos de escolas parceiras. Nesse contexto, o processo de escrita-reflexão também se fez presente.

Nos vários e diversos momentos de escrita, o uso das palavras sofreu certa resistência por parte de alguns licenciandos. Devido a esse fato, foi necessário inicialmente "[...] o rompimento das resistências com a leitura, com os estudos teóricos e com a produção escrita", na direção de superar concepções de que professor de Matemática deve se "[...] ocupar apenas da atividade Matemática" (Bisconsini, Reis \& Borges, 2007, p.1). Assim, a necessidade e a constância da escrita nos levaram a perceber - uns mais, outros menos - que no exercício da profissão docente “[...] escrever é preciso, pesquisar sempre, reconstruir de contínuo nossas aprendizagens" (Marques, 2006, p.13).

Por isso, acreditamos que o PIBID Matemática foi constituído por nós - nesses e com esses movimentos de escrita - como uma oportunidade de percepção, discussão e reflexão dos/sobre aspectos específicos de nossa (futura) profissão.

\subsection{Aproximação da escola com a universidade e da universidade com a escola}

As atividades desenvolvidas no PIBID/Matemática aproximaram, substancialmente, escola e universidade. Nóvoa (2004) nos chama a atenção para a importância dessa inter-relação na formação de professores quando diz que:

É evidente que a Universidade tem um papel importante a desempenhar na formação de professores. Por razões de prestígio, de sustentação científica, de produção cultural. Mas a bagagem essencial de um professor adquire-se na escola, através da experiência e da reflexão sobre a experiência. (Nóvoa, 2004, p. 5)

Nessa direção, ao promover o efetivo contato de graduandos com o futuro ambiente de trabalho, o PIBID/ Matemática proporcionou aos mesmos uma iniciação à prática profissional mais efetiva do que aquela muitas vezes realizada no estágio supervisionado.

Frequentemente, no estágio supervisionado, a presença do licenciando na escola é de um estudante samambaia: "[...] 
fixado no fundo da sala, a observar as atividades da professora e seus alunos, quase de forma decorativa, como uma samambaia" (Lüdke, 2015, p.177). Essa metáfora, usada para nos remeter ao caráter passivo do estudante durante o estágio supervisionado, faz parte de suas fragilidades. Ainda nos momentos de regência desse estagiário, essa postura passiva geralmente permanece; quase sempre as aulas ministradas por ele seguem o roteiro prescrito pelo professor responsável pela turma, sendo, muitas vezes, aulas de exercícios, desprovidas de quaisquer discussões ou problematizações junto ao professor regente da escola dos caminhos a nelas se seguir. Talvez, essa postura do professor, que recebe o estagiário na escola, aconteça justamente pelo primeiro não dimensionar a importância que ele tem na formação inicial do estagiário, por não se considerar co-formador daquele aluno. Esse estado, por assim dizer, do estágio supervisionado tem sido bastante discutido em vários trabalhos (Teixeira, \& Cyrino, 2013, Lopes, Paiva, Pereira, Pozebon, \& Cedros, 2017).

Nossa trajetória no PIBID/Matemática, dentro da licenciatura em Matemática da UFSJ, e nossa proximidade com o estágio supervisionado, mostraram-nos que é necessário lançar novos olhares para esse último, repensando suas limitações e sua inserção na escola. Se considerarmos o estágio supervisionado, conforme indicado nas Diretrizes Curriculares Nacionais para os Cursos de Matemática (Brasil, 2001), como essencial à formação de professores e entendido como um momento oportuno para a capacitação do futuro professor na tomada de decisões, de reflexão sobre práticas e do uso da criatividade na ação pedagógica, tornase imprescindível que ele seja transformado. E experiências do(s) PIBID(s) podem ser inspiração para isso.

A imersão de licenciandos em Matemática no espaço escolar, viabilizada pelas atividades do PIBID/Matemática, não nos trouxe apenas o confronto com as realidades de algumas escolas, mas também a possibilidade de rompermos com barreiras do "ensinar", colocando-nos não mais no lugar de alunos, mas de (futuros) professores.

Tardif \& Raymond (2000, p. 217) afirmam que "[...] saber como viver numa escola é tão importante quanto saber ensinar na sala de aula", e a nossa participação neste projeto foi uma oportunidade ímpar para mais esse aprendizado. De fato, a articulação entre universidade e escola básica aconteceu pelas ações de PIBID/Matemática, que foram oportunidades para que integrássemos conhecimentos práticos e acadêmicos, gerando assim novos saberes à nossa (futura) profissão. Veremos um pouco mais sobre como se deu esse diálogo entre teoria e prática na subseção que segue.

\subsection{Criando movimentos entre teoria e prática}

Reconhecendo a pluralidade das competências necessárias para a formação do educador matemático, o subprojeto de Matemática do PIBID-UFSJ procurou estabelecer um diálogo entre o saber profissional e o saber universitário através do contato com a prática escolar durante a licenciatura. Assim, a escola, bem mais que um local onde seriam aplicados os conhecimentos aprendidos na universidade, pôde ser vista como também um importante ambiente de formação inicial e continuada de professores e potencialmente rico à produção de conhecimentos.

Essa formação se deu através da experiência prática que $\mathrm{o}(\mathrm{s})$ contexto(s) escolar(es) proporcionou/proporcionaram aos futuros docentes, pois "[..] se o trabalho modifica o trabalhador e sua identidade, modifica também, sempre com o passar do tempo, o seu 'saber trabalhar'" (Tardif, 2010, p.57). E assim o é também com o professor, que também se forma no tempo em serviço.

Dessa forma, pela prática por nós exercida dentro das escolas, surgiram tanto obstáculos quanto situações de interação que nos exigiram habilidades que extrapolavam o que conhecíamos até então; desse modo, impulsionados por buscarmos alternativas, recorríamos àqueles que em nosso grupo possuíam mais experiência acumulada quanto também buscávamos respaldo em leituras e trabalhos que pudessem nos auxiliar, se necessário fosse, a reorientar nossas práticas e percepções. Esse desejo de enfrentar os desafios emergentes do ambiente escolar, levaram-nos ainda a refletir criticamente sobre nossas práticas, pois compreendíamos (e ainda compreendemos) que somente o domínio do conteúdo matemático não é o que determina qualidade no seu ensino. Assim,

[...] ao abandonar o conceito obsoleto que estabelece que a formação é a atualização científica, didática e psicopedagógica dos professores, assumimos a crença de que ela ajuda a descobrir a teoria, ordená-la, fundamentá-la, revisá-la e construí-la”. (Imbernón, 2015, p. 81)

E, é nessa direção que a reflexão possibilitada pelo PIBID se tornou essencial para que não mecanizássemos nossa prática, passando a trabalhar de forma repetitiva, reproduzindo assim o que já estava pronto e o que era mais acessível, fácil ou simples (Fiorentini, \& Castro, 2003).

Nas salas de aula, lidamos com dificuldades apresentadas por alunos do ensino básico - como a capacidade de abstração, medos ou traumas de alguns conteúdos matemáticos, inexperiência com o uso de régua e compasso, falta de motivação para os estudos, a aprendizagem mecanizada de alguns conteúdos e a indisciplina, que é um problema que tem ocupado um espaço cada vez maior no cotidiano escolar (Souto, \& Paiva, 2010). Outro obstáculo enfrentado diz respeito à infraestrutura escolar, às vezes inadequada para que trabalhássemos junto às turmas com softwares computacionais. Além dessas condições, enquanto iniciantes na docência, precisávamos ainda lidar com nossa insegurança em gerir uma sala de aula, com nossa inexperiência em lidar com imprevistos, com a necessidade por transformar a Matemática num conteúdo acessível a todos, e com experiências de trabalho com alunos tão diferentes entre si.

Muitos dos desafios anteriormente elencados, encontrados 
no âmbito escolar, eram compartilhados pelos bolsistas de iniciação à docência; e, para a superação dos mesmos, foram fundamentais a reflexão e a investigação sobre nossas primeiras práticas profissionais possibilitadas pelo PIBID/ Matemática. Na busca por essa superação, direcionamos esforços para vislumbrar nossas posteriores experiências através da lente dos saberes teóricos.

Além dos estudos previamente realizados no meio acadêmico e dos saberes produzidos a partir de outras fontes, de naturezas sociais variadas ${ }^{2}$, as pesquisas no âmbito do PIBID também contribuíram para o refletir e o (re)pensar sobre nossa prática docente. Já dizia Freire que "não há ensino sem pesquisa e pesquisa sem ensino" (Freire, 2016, p. 30), ressaltando que a pesquisa e a indagação devem ser atividades naturais à prática do educador. Ponte (2004) explica como essa pesquisa se insere no trabalho docente, salientando que

Não se trata de transformar os professores em pesquisadores profissionais. Trata-se de reforçar a competência profissional do professor, habilitando-o a usar a pesquisa como uma forma, entre outras, de lidar com os problemas com que se defronta" (Ponte, 2004, p. 2).

"Quais profissionais passam ou já passaram por situações parecidas?”, “o que esses profissionais fizeram para superálas?", "quais maneiras possíveis de se trabalhar com um mesmo conteúdo matemático?" e “quais práticas podem estimular o aprendizado dos alunos?", foram algumas das indagações que orientaram nossas pesquisas. Autores como Regina Célia Grando, e seus estudos sobre a importância do jogo no processo de ensino-aprendizagem da Matemática (Grando, 2000), e Ubiratan D'Ambrosio, com sua proposta de uma educação matemática para a paz (D'Ambrosio, 2012) e a valorização da matemática produzida por diversos grupos culturais (D’Ambrosio, 2013), auxiliaram-nos, com suas obras, em nossas reflexões sobre nossas práticas e nas tentativas de criarmos novas oportunidades de aprendizado para os adolescentes e jovens com os quais trabalhávamos.

Sérgio Lorenzato também foi um dos autores que contribuiu para que começássemos a refletir sobre a finalidade dos materiais didáticos de Matemática antes de levá-los para a sala de aula, alertando-nos que o material por si só não apresentaria caráter educativo sem uma prévia reflexão acerca de suas possibilidades (Lorenzato, 2012). Rubem Alves, em um de seus escritos, incentivou-nos a nos tornarmos educadores jequitibás, cheios de fases, possuidores de uma identidade, repletos de 'estórias' para contar... E nos desencorajou a sermos professores eucaliptos: enfileirados, todos iguais, com finalidade de lucro e prontos para substituirmos as velhas árvores (Alves, 1980). Já Paulo Freire nos ensinou a trazer mais ética, humanidade, amorosidade e gentileza para nossa prática docente, reconhecendo o quão emancipatória ela poderia se tornar para os estudantes das escolas onde atuávamos (Freire, 2016).

Algumas respostas foram encontradas nessas e em outras produções teóricas, ao passo que novas questões surgiram. Muitos foram os ecos dos autores que subsidiaram nossas práticas. Parte deles são apresentados na próxima subseção.

\section{5 (Re)traduzindo saberes escolares: estratégias e materiais didáticos para leitura do mundo pela Matemática}

À luz de ideias dos autores já aqui citados e de muitos outros que compuseram nosso repertório de leituras, tendo em conta observações nas escolas e as demandas educacionais identificadas em distintos contextos escolares, um de nossos objetivos na iniciação à docência foi o de retraduzir e adaptar saberes escolares para as atividades que propúnhamos aos alunos das escolas. Uma significativa produção de materiais e estratégias didático-pedagógicas aconteceu ao longo dos 10 anos do PIBID/Matemática na UFSJ. No que segue, daremos destaque a algumas delas.

Uma dessas estratégias que adotamos foi a utilização de projetos no ensino. Segundo as Orientações Educacionais Complementares aos Parâmetros Curriculares Nacionais, “o ensino por meio de projetos, além de consolidar a aprendizagem, contribui para a formação de hábitos e atitudes e para a aquisição de princípios, conceitos ou estratégias que podem ser generalizados para situações alheias à vida escolar" (Brasil, 2002, p.56).

Tínhamos em vista, tanto na elaboração quanto no desenvolvimento desses projetos, que as ações neles realizadas precisariam ser oportunidades para que os alunos pudessem perceber os conteúdos matemáticos e a linguagem matemática como auxiliares na compreensão de fenômenos, na expressão de ideias, na leitura do mundo.

Um exemplo de projeto de ensino realizado foi o "Eleições na escola". Nele, alunos de turmas do $1^{\circ}$ ano do Ensino Médio participaram de todo o processo que envolveu uma eleição fictícia na escola. Orientados pelos bolsistas do PIBID-UFSJ de Matemática, cada grupo de estudantes se propôs a defender um candidato fictício a presidente, elaborando suas propostas para a melhoria do mundo e da escola. Houve o tempo da campanha política e da pesquisa eleitoral, quando elementos matemáticos foram fortemente explorados pelos alunos e pelos bolsistas de iniciação à docência.

$\mathrm{Na}$ reta final do trabalho, aconteceu um debate entre os grupos que propuseram as candidaturas. Contamos também com a parceria firmada entre escola, universidade e a Justiça Eleitoral da Comarca de São João del-Rei, quando muitos dos alunos aprenderam a usar uma urna eletrônica e tiveram esclarecimentos pela equipe técnica do Cartório Eleitoral de como são calculados os votos válidos, brancos e nulos, em uma palestra ministrada na escola para algumas turmas. Para a eleição propriamente dos candidatos fictícios, da qual

2 Segundo Tardif (2010), o saber docente é plural, de fontes e naturezas sociais variadas (escola, família, faculdade, curso de reciclagem...). Ainda, segundo esse o autor, o saber do professor ultrapassa o seu saber individual e o saber sobre seu trabalho. 
participaram os alunos de toda a escola, utilizamos uma urna convencional e cédulas de papel, pois na data prevista, a urna eleitoral eletrônica não pôde ser emprestada pela Justiça Eleitoral.

Além do aprendizado sobre estatística e probabilidade propiciado pelo projeto, os alunos puderam aprender também sobre a responsabilidade social do ato de votar, os mecanismos das pesquisas eleitorais e a importância do sistema eleitoral brasileiro, tendo oportunidades de refletir sobre o próprio exercício da cidadania. Evidenciamos aqui a amplitude de experiências educativas que um projeto como esse pode proporcionar no âmbito escolar.

Enquanto bolsistas do PIBID/Matemática, pudemos aprender que é possível desenvolver um trabalho educativo comprometido com a democracia e aberto à pluralidade e ao debate de ideias e, assim, melhor compreendermos a importância do professor como agente social, político, crítico e reflexivo. Afinal, não faz sentido insistir em uma educação para todos se não conseguirmos através dela mais qualidade de vida e dignidade para a humanidade (D'Ambrosio, 2013). Com esse trabalho, experimentamos a possibilidade de, considerando uma situação social, por meio da lente da Matemática escolar, proporcionar momentos de reflexões críticas e autônomas para todos os envolvidos no projeto.

Outro projeto desenvolvido foi o "Desvendando a Matemática na arte de construir mandalas", feito com alunos do $8^{\circ}$ ano do Ensino Fundamental. Inicialmente, foi feito o estudo de círculos, circunferências, simetrias e rotações com vistas à construção de mandalas, utilizando lápis, régua e compasso. As construções despertaram a curiosidade de muitos alunos quanto a esse elemento milenar em diversas culturas; mitos sobre mandalas, como a ideia de que seria um símbolo diabólico, também puderam ser descontruídos.

Na finalização desse trabalho, uma oficina sobre a criação de mandalas foi ofertada pelos bolsistas do PIBID/Matemática às turmas do $8^{\circ}$ ano que inicialmente estavam no projeto $\mathrm{e}$ para aqueles da comunidade escolar que se interessaram pela temática. Utilizando elementos geométricos e também a criatividade e habilidades artísticas, os alunos puderam elaborar diversas construções mandalísticas.

Pelas nossas experiências, tanto na realização da oficina quanto no desenvolvimento do projeto como um todo, pudemos constatar algumas dificuldades dos adolescentes com a geometria e com objetos de desenho geométrico, provavelmente ainda resultado do abandono do ensino da geometria ocorrido no Brasil ao longo do século XX (Pavanello, 1993).

A execução do projeto sobre mandalas permitiu-nos direcionar o estudo da Matemática tendo nele uma finalidade artística e cultural. Talvez por isso muitos alunos se mostraram receptivos às atividades que envolveram o uso de compasso e régua e a abordagem de alguns elementos geométricos.
Situações como essa, vivida no projeto de mandalas, levaramnos a compreender ser possível incorporar a Matemática a práticas educativas de modo que seu conteúdo contribua na consecução de objetivos outros vinculados a outra área, com a de Artes, nesse caso. De forma recíproca, pelo trabalho que pudemos realizar nesse projeto, a escola que o acolheu tornouse partícipe de nossa formação ao nos permitir incorporar ao nosso "saber-fazer" "aquele tipo de experiência pedagógica.

Para promover o estudo da geometria associado a manifestações artísticas, trabalhamos junto a alunos dos $7^{\circ}$ e $8^{\circ}$ anos de uma escola parceira em outro projeto, cujo fio condutor foram obras do artista pernambucano Romero Brito. Os conteúdos abordados ao longo do projeto com cada uma das turmas estavam previstos nos planejamentos anuais dos professores de Matemática e foram tratados a partir da temática de gravuras de Romero Brito. Como produto final desse projeto, em trabalho conjunto com os alunos e utilizando releituras que eles haviam feito das gravuras do referido artista, realizamos a restauração e revitalização de um armário de livros didáticos da escola.

Naquele contexto escolar, um armário esquecido se tornou cor no ambiente. Nossa intenção, para além dos objetivos estabelecidos com relação ao conteúdo matemático, era que a mudança visual ocorrida naquele ambiente fosse marca do trabalho daqueles alunos na escola, podendo inspirar a muitos quanto à possibilidade de suas ações poderem transformar o ambiente escolar para além de suas aparências.

O projeto "Conhecendo o que consumimos: o que nos dizem os rótulos e embalagens?" discutiu vida saudável e alimentação equilibrada através do estudo de rótulos de embalagens de produtos alimentícios, usando ideias matemáticas como importantes ferramentas nessa leitura. O diálogo estabelecido inicialmente sobre o tema "Rótulos e Embalagens" com os alunos do $1^{\circ}$ ano do Ensino Médio ajudou-nos a trazê-los para o centro das discussões. Perguntas como: Para que servem os rótulos? Que tipo de informações eles apresentam? Que tipo de informações eles deveriam apresentar? Existe alguma normatização que regulamente o conteúdo dos rótulos? E das embalagens? Para que elas servem?, foram feitas ao grupo e auxiliaramnos na sensibilização de seus integrantes quanto ao tema. A partir daí, demos início ao desenvolvimento de atividades que focaram a leitura de rótulos de embalagens - escolhidos e trazidos pelos próprios alunos - visando à exploração de noções matemáticas em cálculos e proporções, estabelecidos a partir dos elementos da tabela nutricional de cada produto, e no estudo de grandezas e unidades de medidas, considerandose o peso e as dimensões das embalagens dos produtos.

Acreditamos que, por meio desse projeto, os alunos tiveram uma oportunidade de perceber a importância do olhar crítico e consciente sobre aquilo que consumimos e, nesse processo, viram a Matemática como ferramenta indispensável. 
Feitas nossas intervenções baseadas em trabalhos em grupo, pesquisas individuais e discussões coletivas, os alunos produziram, ao final do projeto, cartazes relacionados à alimentação saudável que foram divulgados no espaço escolar.

Outra estratégia didático-pedagógica utilizada ao longo dos anos do PIBID/Matemática foram os jogos educativos. Como vemos nas Orientações Educacionais Complementares aos Parâmetros Curriculares Nacionais,

Os jogos e brincadeiras são elementos muito valiosos no processo de apropriação do conhecimento. Permitem o desenvolvimento de competências no âmbito da comunicação, das relações interpessoais, da liderança e do trabalho em equipe, utilizando a relação entre cooperação e competição em um contexto formativo". (Brasil, 2002, p.56).

Grando (2000) também disserta sobre os benefícios da utilização de jogos, mencionando as "[...] vantagens no processo de criação e construção de conceitos, quando possível, através de uma ação comum estabelecida a partir da discussão matemática entre os alunos e entre o professor e os alunos" (Grando, 2000, p. 32). A partir da reflexão sobre tais considerações, utilizamos com os alunos atendidos pelo PIBID/ Matemática alguns jogos, por meio dos quais poderíamos trabalhar alguns conceitos matemáticos.

Um desses jogos foi o "Dominó de frações", trabalhado com alunos do $6^{\circ}$ ano do Ensino Fundamental. Muito parecido com o dominó convencional, o jogo segue as mesmas regras; a diferença é que no lugar de pontos em suas peças, ele apresenta números fracionários e representações pictóricas de frações, as quais deveriam ser devidamente conectadas pelos alunos durante o jogo. Jogando em duplas, o ganhador seria aquele que conseguisse encaixar todas suas peças.

O objetivo inicial era o de abordar o conteúdo frações de uma forma alternativa. Para além disso, conseguimos também que o jogo funcionasse como instrumento de avaliação da compreensão daquele conteúdo; visávamos observar, em especial, aqueles alunos que, em aulas tradicionais, assumiam uma posição mais passiva, esquivando-se de sanar suas eventuais dúvidas (Lara, 2004). Pudemos perceber assim, a importância de se criar mais e diferentes oportunidades de aprendizado e de avaliação, que alcancem os mais variados tipos de alunos: os que têm facilidade em aprender de forma tradicional, aqueles se desenvolvem melhor em jogos e competições, os que se identificam mais com expressões artísticas na educação, dentre tantos outros.

Além do mais, como vemos em Tinti (2012), a confecção e uso de recursos metodológicos variados não são só benéficas para o aluno, como também contribuem para a formação do futuro professor. $\mathrm{O}$ graduando em licenciatura, ao utilizar esse recurso no contexto de iniciação à docência, pode ter a oportunidade de refletir sobre as potencialidades e limitações daquele material, de elaborar mudanças em suas regras ou estrutura e de aumentar o aproveitamento do recurso quando novamente utilizá-lo em uma sala de aula (Flemming \& Mello, 2003).
Outra opção que fizemos, foi ministrar aulas que tratariam conteúdos específicos, dentro da sequência de aulas planejadas pelo professor responsável pela turma. Primeiramente, estabelecíamos uma conversa com esse professor tanto para a escolha da temática a abordar quanto para identificarmos - a partir da experiência daquele profissional - algumas potenciais dificuldades que os alunos apresentariam com relação ao conteúdo escolhido. Em seguida, elaborávamos um plano de aula prevendo atividades que oportunizassem tocar naquelas dificuldades e problematizá-las junto à turma.

Uma das aulas ministradas foi com alunos do $6^{\circ}$ ano do Ensino Fundamental e nela tratamos sobre o cálculo de área de alguns polígonos. Vale lembrar que, nesse momento da escolarização, o objetivo não era apresentar formalmente fórmulas para o cálculo de áreas e, sim, deduzir junto ao grupo uma maneira de determinar a área de cada um dos polígonos trabalhados.

Inicialmente, tratando de retângulos e quadrados, utilizamos diversas dessas figuras quadriculadas em seu interior como material didático para esta atividade. O que fora pedido aos alunos era para que registrassem a quantidade de quadradinhos que havia no interior das figuras, bem como as dimensões (altura e largura) daqueles quadriláteros. Após discussões estabelecidas entre os alunos, o grupo encontrou uma relação entre as dimensões das figuras e a quantidade total de quadradinhos - o número total de quadradinhos no interior de cada um daqueles quadriláteros era igual ao produto das suas dimensões.

Na segunda parte da intervenção, trabalhamos com figuras triangulares; com elas, os alunos sentiram dificuldades em determinar a altura dos triângulos como a medida do segmento vertical (traçado a partir de um vértice do triângulo ao seu lado oposto). Dessa forma, reelaboramos esta parte da atividade, duplicando as áreas dos triângulos, de forma que originassem um quadrado ou retângulo, com uma das dimensões sendo a base tomada do triângulo e a outra sendo a altura do triângulo relativa à base considerada. Assim, como os alunos já haviam trabalhado na primeira parte da atividade com o cálculo de áreas de quadrados e retângulos, eles conseguiram determinar as áreas dos triângulos dividindo por dois a área dos retângulos ou quadrados construídos.

Ao fim dessa intervenção, pudemos perceber o quanto foi importante a ação sobre um objeto visual-tátil no processo de ensino-aprendizagem daquele conteúdo. Entretanto, como nos aponta Lorenzato (2012), a aprendizagem não é consequência apenas da utilização do objeto e material-didático, mas, sim, do aprofundamento de reflexões que ele pode causar sobre uma ação.

De forma geral, o trabalho com variados materiais e estratégias didáticas, pôde agregar a nossa formação diversos saberes experienciais que se desenvolvem apenas no contexto escolar, em que o professor está sujeito a obstáculos e interações (Tardif, 2010). Com o passar do tempo, a produção desses saberes nos auxiliou na integração com a escola, com 
seus alunos e professores (de Matemática), permitindo-nos um maior entendimento sobre a profissão docente e servindonos como objeto de reflexões sobre o ser professor.

A oportunidade de repensar os fundamentos acadêmicos para colocá-los em ação sob a forma de projetos, jogos e intervenções, possibilitou o diálogo entre teoria e prática, validando a parceria universidade-escola. As práticas do PIBID/Matemática permitiram uma aproximação efetiva com a profissão docente ainda na formação inicial, ampliando o repertório de experiências escolares, as quais poderão permitir aos futuros professores que passaram por esse programa se posicionar de modo mais seguro e confiante, e porque não esperançoso, frente aos problemas reais da escola pública brasileira.

\section{De Fios Entrelaçados a Outras Tessituras}

O PIBID foi, sem dúvidas, um programa de formação de professores de abrangência nacional sem precedentes na história do Brasil. Neste artigo, buscamos apresentar alguns dos que foram para nós sentidos desse programa para/na formação de professores de Matemática: a importância do trabalho coletivo, do registro e da reflexão para produção de novos saberes de prática profissional, a aproximação que se estabeleceu entre escola-universidade, os movimentos entre teoria e prática e as possibilidades de (re)traduzir saberes escolares para leitura do mundo pela Matemática.

Por permitir aos bolsistas uma aproximação com a prática docente e a dinâmica escolar, o PIBID contribuiu para a formação de licenciandos e professores, com a criação de espaços de aprendizagem a partir da prática, das vivências e dos diálogos estabelecidos entre diversos atores educacionais. No contexto desse programa, de fato, a escola tornou-se campo da formação (inicial e continuada) de professores.

Viabilizou ainda a construção de variadas práticas educativas em escolas, beneficiando não apenas os participantes do programa, mas uma significativa parcela da comunidade escolar. Essas práticas implementadas, muitas sob o enfoque de metodologias alternativas de ensino, foram desenvolvidas a partir da chamada "corresponsabilidade nos processos educativos": o vínculo universidade-escola, representado pela parceria entre professor universitário, professor do ensino básico e bolsistas licenciandos, permitiu uma reflexão acerca de novas atividades (jogos, projetos e intervenções) que geraram mais oportunidades de aprendizado para os diferentes estudantes da escola básica. De forma mútua, o ato e o hábito de refletir sobre as atividades e suas potencialidades foi oportunidade para produção de conhecimentos tanto para o licenciando bolsista, como também para os professores envolvidos no PIBID (Rubo, Fernandes, Penteado, \& Mendonça, 2015).

Enquanto professoras, da educação básica e do ensino superior, constantemente recorremos aos saberes produzidos ao longo de nossa participação do PIBID/Matemática como quem lança mão a uma "senha pessoal e intransferível", que dá acesso a um conteúdo importante, singular e necessário, que hoje percebemos como imprescindível em muitos momentos de nossa prática profissional. Rememorar nossa participação no PIBID e registrá-la neste escrito nos permitiu olhar para trás e juntar, como num quebra-cabeças, peças da nossa história que nos constituem como professoras.

O contato "antecipado" com a prática profissional, proporcionado pelo PIBID para os licenciandos, amadureceu o exercício da profissão docente. Isso porque o programa reforçou a ideia da "[...] complexidade e valor da atividade docente, que não pode e não deve prescindir da reflexão e da investigação sobre a prática" (Souto et al., 2010, p.7).

Compreendemos, assim como Garcia (2010), que o professor em início de carreira, nos primeiros anos de docência como profissional habilitado, vive tensões e conflitos que, para muitos, acabam culminando no abandono da carreira docente. No caso específico de duas autoras deste artigo, os aprendizados gerados pela participação no PIBID/ Matemática tornaram o início de carreira menos árduo. Acreditamos que isso se deva, em grande parte, ao repertório docente que constituímos no tempo do PIBID/Matemática, o que possibilitou uma transição mais suave da passagem de estudantes de uma licenciatura a professoras de fato. Apesar dessa situação particular, não podemos perder vista, como nos diz Cochran-Smith, que:

Para permanecer no ensino, hoje e amanhã, os professores necessitam de condições na escola que os apoiem e pressuponham oportunidades para trabalhar com outros educadores em comunidades de aprendizagem profissional em vez de fazê-lo de forma isolada. (Cochran-Smith, 2004 apud Garcia, 2010, p. 30)

Nessa direção, apontamos como crucial ao incentivo à docência e à valorização do magistério - além de programas de iniciação à docência durante a licenciatura -, que haja implementações de políticas públicas que estabeleçam ações de apoio, acolhida e acompanhamento dos professores em início de carreira.

Temos clareza da complexidade do ser professor. Contudo, mesmo diante de situações adversas às quais estamos sujeitos profissionalmente, o PIBID permitiu-nos nos reconhecer como capazes de problematizar e questionar teorias e práticas e, nesse interim, também como produtoras de conhecimento. Independentemente das circunstâncias e do local de trabalho, podemos "[...] analisar, discutir, refletir, encaminhar e/ou redirecionar nossas ações e estratégias de trabalho" (Rubo et al., 2015, p. 164).

Passado o PIBID, temos ainda desafios (muitos) à formação de professores de Matemática no Brasil, mas com perspectivas de que, pelas vivências experimentadas e problematizadas durante o tempo desse programa, se incorporem práticas educativas, junto a professores e a futuros professores, que possam contribuir com transformações pelo fortalecimento da educação básica e da profissão docente. 


\section{Referências}

Alves, R. (1980). Conversas com quem gosta de ensinar. Campinas: Autores Associados.

Bisconsini, V.R., Reis, C.A.R., \& Borges, E.C. (2007). Memorial de Estágio como possibilidade de desenvolvimento da capacidade de produção escrita do futuro professor de Matemática. In: Encontro Nacional de Educação Matemática, 9., Belo Horizonte - MG, Anais... Belo Horizonte.

Brasil (1998). Secretaria de Educação Fundamental. Parâmetros curriculares nacionais: Matemática. Brasília: MEC /SEF.

Brasil (2001). Parecer CNE/CES no 1.302/2001, aprovado em 6 de novembro de 2001, sobre as Diretrizes Curriculares Nacionais para os Cursos de Matemática, Bacharelado e Licenciatura. Brasília: MEC.

Brasil (2002). Ministério da Educação. Secretaria da Educação Média e Tecnológica. Orientações Educacionais Complementares aos Parâmetros Curriculares Nacionais Ciências da Natureza e suas Tecnologias. Brasília: MEC.

Brasil (2009). Portaria Normativa no 16, de 23 de dezembro de 2009. Dispõe sobre o PIBID - Programa Institucional de Bolsa de Iniciação à Docência. Disponível em: http://www. pibid.ufms.br/Portaria_Normativa_16_23 12_2009.pdf. Acesso em: maio/2018

Brasil. (2010). Decreto no 7.219, de 24 de junho de 2010. Dispõe sobre o Programa Institucional de Bolsa de Iniciação à Docência - PIBID e dá outras providências. Disponível em: http://www.planalto.gov.br/ccivil 03/ ato2007-2010/2010/ decreto/d7219.htm. Acesso em: maio/2018.

Brasil. (2014). Ministério da Educação. Secretaria de Educação Superior. Plano de Desenvolvimento Institucional da Universidade Federal de São João del-Rei. Brasília: MEC/ SESu.

D’Ambrosio, U. (2013). Etnomatemática: Elo entre as tradições e a modernidade. Belo Horizonte: Autêntica.

D’Ambrosio, U. (2012). Educação Matemática: Da teoria à prática. Campinas: Papirus.

Fiorentini, D., \& Castro, F.C. (2003). Tornando-se professor de matemática: o caso de Allan em prática de ensino e estágio supervisionado. In: D., Fiorentini. Formação de professores de matemática: explorando novos caminhos com outros olhares, (pp. 121-156). Campinas: Mercado de Letras.

Flemming, D.M., \& Mello, A.C.C. (2003). Criatividade e jogos didáticos. São José: Saint Germain.

Freire, P. (1991). A educação na cidade. São Paulo: Cortez.

Freire, P. (2016). Pedagogia da autonomia: Saberes necessários à prática educativa. Rio de Janeiro: Paz e Terra.

Garcia, C.M. (2010) O professor iniciante, a prática pedagógica e o sentido da experiência. Revista Brasileira de Pesquisa Sobre a Formação Docente, 2, 11-49.

Gatti, B.A., \& Barreto, E.S.S. (2009). Professores do Brasil: Impasses e desafios. Brasília, Unesco.

Grando, R.C. (2000). O conhecimento matemático e o uso de jogos na sala de aula. Campinas, SP: Tese de Doutorado, Universidade Estadual de Campinas, Campinas, SP, Brasil.

Imbernón, F. (2015). Novos desafios da docência no século XXI: a necessidade de uma nova formação docente. In: A.S., Celestino, B.A., Gatti, M.G.N., Mizukami, M.D.S. Pagotto, M.L.Spazziani. Por uma revolução no campo da formação de professores, (pp. 171-186) São Paulo: Editora Unesp.
Lara, I.C.M.D. (2004). O jogo como estratégia de ensino de $5^{\mathrm{a}}$ a 8 série. In: Encontro Nacional de Matemática - Educação Matemática: um compromisso social, 8. Recife - PE, Anais... Recife. Disponível em: http://www.sbembrasil.org.br/files/ viii/arquivos/index_1.htm. Acesso em: junho. 2017.

Larrosa, J.B. (2002). Notas sobre a experiência e o saber de experiência. Rev. Bras. Educ, 19, 20-8.

Lopes, A.R.L.V., Paiva, M.A.V., Pereira, P.S., Pozebon, S., \& Cedros, W.L. (2017). Estágio Curricular Supervisionado nas licenciaturas em Matemática: reflexões sobre as pesquisas brasileiras. Zetetiké, 25(1),75-93.

Lorenzato, S. (2012). Desenvolvimento e uso de materiais didáticos no ensino de matemática. In: S., Lorenzato. $O$ Laboratório de Ensino de Matemática na Formação de Professores (pp.3-55). Campinas: Autores Associados.

Lüdke, M. (2015). Estágio Supervisionado: substantivo fictício? In: A.S, Celestino, B.A, Gatti, M.G.N., Mizukami, M.D.S. Pagotto, \& M.L., Spazziani Por uma revolução no campo da formação de professores (pp.171-186). São Paulo: Editora Unesp.

Marques, M. O. (2006). Escrever é preciso; o princípio da pesquisa. Ijuí: Editora Unijuí.

Minas Gerais (2007). SEE Conteúdo Básico Comum (CBC) Matemática - Ensino Fundamental e Médio. Disponível em: http:// crv.educacao.mg.gov.br/SISTEMA CRV/index.aspx?\&us$\mathrm{r}=$ pub\&id_projeto $=27 \&$ id_objeto $=39143 \&$ id pai $=38935 \&$ tipo $=\operatorname{txg} \& n 1=\& n 2=$ Proposta $\% 20$ Curricular $\% 20-\% 20 \mathrm{CB}-$ C\&n3=Ensino $\% 20 \mathrm{M} \% \mathrm{C} 3 \% \mathrm{~A} 9$ dio\&n $4=$ Matem $\% \mathrm{C} 3 \% \mathrm{~A} 1 \mathrm{ti}-$ $\mathrm{ca} \& \mathrm{~b}=\mathrm{s} \&$ ordem $=\mathrm{campo} 3 \& \mathrm{cp}=\mathrm{B} 53 \mathrm{C} 97 \& \mathrm{cb}=\mathrm{mma}$. Acesso em: junho. 2018

Nóvoa, A. (2001). Professor se forma na escola. Entrevista concedida em 01 mai. Disponível em: https://novaescola.org. br/conteudo/179/entrevista-formacao-antonio-novoa.

Nóvoa, A. (2004). Novas disposições dos professores: A escola como lugar da formação. Sistema integrado de bibliotecas repositório. Disponível em: http://repositorio.ul.pt/ handle/10451/685. Acesso em: junho 2018

Oliveira, M.C.S. (2014). Sentidos do Programa Institucional de Bolsa de Iniciação à Docência (Pibid) na formação de professores: um estudo com egressos da universidade federal de São João del-Rei. Dissertação (Mestrado em Educação), Universidade Federal de São João del-Rei, São João del-Rei, MG, Brasil.

Pavanello, R.M. (1993). O abandono do ensino da Geometria no Brasil: causas e consequências. Zetetiké, 1(1), 7-17.

Ponte, J.P. (2004). Pesquisar para compreender e transformar a nossa.A. própria prática. Educar em Revista, 24, 37-66.

Rubo, E.A.A., Fernandes, M.J.D.S., Penteado, M.G., \& Mendonça, S.G.D.L. (2015). Do núcleo de Ensino ao Pibid: a contribuição da Unesp à formação de professores. In: CD. Silva Junior, B.A., Gatti, M.D.C.N., Mizukami, M.D.S., Pagotto, \& M.D. Lourdes. Por uma revolução no campo da formação de professores, (p.153 -168). São Paulo: Unesp.

Souto, R.M.A., \& Paiva, P.H.A.A. (2010). O significado da indisciplina e suas relações com o fracasso escolar em Matemática na visão de professores da escola básica. In: Encontro Nacional de Educação MatemátiSca: Educação Matemática, cultura e diversidade, 10. Salvador - BA, Anais... Salvador.

Souto, R.M.A., Castro, M.C.A.; Reis, D.A., \& Oliveira, M.C.S. (2010). PIBID - Programa Institucional de Bolsa de Iniciação à Docência: a experiência da equipe de Matemática da UFSJ. 
In: Encontro Nacional de Educação Matemática: Educação Matemática, cultura e diversidade. 10. Salvador - BA, Anais... Salvador.

Tardif, M. (2010) Saberes docentes e formação profissional. Petrópolis: Vozes.

Tardif, M., \& Raymond, D. (2000). Saberes, tempo e aprendizagem do trabalho no magistério. Educação \& Sociedade, 21(217), 73.

Teixeira, B.R., \& Cyrino, M.C.C.T. (2013). O estágio supervisionado em cursos de licenciatura em Matemática: um panorama de pesquisas brasileiras. Educação Matemática Pesquisa, 15(1) 29-49.

Tinti, D.S., \& Manrique, A.L. (2016). Teoria e prática na formação de professores que ensinam Matemática: que caminhos apontam experiências com o PIBID e OBEDUC?. Educação Matemática em Revista, 49B, 98-106.

Tinti, D.S. (2012). PIBID: um estudo sobre suas contribuições para o processo formativo de alunos de Licenciatura em Matemática da PUC-SP. Dissertação (Mestrado em Educação Matemática), Pontifícia Universidade Católica de São Paulo, São Paulo, SP, Brasil. 